University of Nebraska - Lincoln

DigitalCommons@University of Nebraska - Lincoln

Publications from USDA-ARS / UNL Faculty

U.S. Department of Agriculture: Agricultural

Research Service, Lincoln, Nebraska

2011

\title{
PhenologyMMS: A program to simulate crop phenological responses to water stress
}

\author{
Gregory S. McMaster \\ USDA-ARS-NPA, greg.mcmaster@ars.usda.gov \\ DA Edmunds \\ USDA-ARS-NPA \\ W.W. Wilhelm \\ USDA-ARS-NPA \\ D.C. Nielsen \\ USDA-ARS-NPA \\ P.V.V. Prasad \\ Kansas State University \\ See next page for additional authors
}

Follow this and additional works at: https://digitalcommons.unl.edu/usdaarsfacpub

Part of the Agricultural Science Commons

McMaster, Gregory S.; Edmunds, DA; Wilhelm, W.W.; Nielsen, D.C.; Prasad, P.V.V.; and Ascough, J.C. II, "PhenologyMMS: A program to simulate crop phenological responses to water stress" (2011).

Publications from USDA-ARS / UNL Faculty. 865.

https://digitalcommons.unl.edu/usdaarsfacpub/865

This Article is brought to you for free and open access by the U.S. Department of Agriculture: Agricultural Research Service, Lincoln, Nebraska at DigitalCommons@University of Nebraska - Lincoln. It has been accepted for inclusion in Publications from USDA-ARS / UNL Faculty by an authorized administrator of DigitalCommons@University of Nebraska - Lincoln. 
Authors

Gregory S. McMaster, DA Edmunds, W.W. Wilhelm, D.C. Nielsen, P.V.V. Prasad, and J.C. Ascough II 
Application note

\title{
PhenologyMMS: A program to simulate crop phenological responses to water stress
}

\author{
Gregory S. McMaster $^{a, *}$, D.A. Edmunds ${ }^{a}$, W.W. Wilhelm ${ }^{b, 1}$, D.C. Nielsen ${ }^{c}$, P.V.V. Prasad ${ }^{d}$, J.C. Ascough II ${ }^{a}$ \\ ${ }^{a}$ USDA-ARS-NPA, Agricultural Systems Research Unit, 2150 Centre Ave., Bldg. D, Suite 200, Fort Collins, CO 80526, USA \\ b USDA-ARS-NPA, Agroecosystems Management Research Unit, 120 Keim Hall, University of Nebraska, Lincoln, NE 68583, USA \\ ${ }^{C}$ USDA-ARS-NPA, Central Plains Resource Management Unit, Central Great Plains Research Station, 40335 County Rd. GG, Akron, CO 80720, USA \\ ${ }^{\mathrm{d}}$ Dept. of Agronomy, Throckmorton Hall, Kansas State University, Manhattan, KS 66506, USA
}

\section{A R T I C L E I N F O}

\section{Article history:}

Received 6 June 2010

Received in revised form 29 March 2011

Accepted 11 April 2011

\section{Keywords:}

Simulation model

Decision support systems

Crop development

Growth stages

Crop management

Seedling emergence

\begin{abstract}
A B S T R A C T
Crop phenology is fundamental for understanding crop growth and development, and increasingly influences many agricultural management practices. Water deficits are one environmental factor that can influence crop phenology through shortening or lengthening the developmental phase, yet the phenological responses to water deficits have rarely been quantified. The objective of this paper is to provide an overview of a decision support technology software tool, PhenologyMMS V1.2, developed to simulate the phenology of various crops for varying levels of soil water. The program is intended to be simple to use, requires minimal information for calibration, and can be incorporated into other crop simulation models. It consists of a Java interface connected to FORTRAN science modules to simulate phenological responses. The complete developmental sequence of the shoot apex correlated with phenological events, and the response to soil water availability for winter and spring wheat (Triticum aestivum L.), winter and spring barley (Hordeum vulgare L.), corn (Zea mays L.), sorghum (Sorghum bicolor L.), proso millet (Panicum milaceum L.), hay/foxtail millet [Setaria italica (L.) P. Beauv.], and sunflower (Helianthus annus L.) were created based on experimental data and the literature. Model evaluation consisted of testing algorithms using "generic" default phenology parameters for wheat (i.e., no calibration for specific cultivars was used) for a variety of field experiments to predict developmental events. Results demonstrated that the program has general applicability for predicting crop phenology and can aid in crop management.
\end{abstract}

Published by Elsevier B.V.

\section{Introduction}

Phenology, or the relationship between climate and the sequence and timing of developmental events or stages, provides a foundation for understanding crop development and growth. Farmers increasingly are basing management on crop developmental stages to enhance economic crop yields while maintaining environmental quality. For instance, as non-agricultural demand for water increases in many arable lands, timing limited irrigation water with critical developmental stages to maximize yield is receiving much interest. Of similar importance, accurate prediction of developmental stages is needed in crop simulation models and decision support aids. Fortunately, a long history of research in plant development and phenology has created a significant understanding and ability to predict developmental events. This is founded on the fundamental concept that plant development is orderly and predictable (Rickman and Klepper, 1995; McMaster, 2005). The genetics of the plant determines the pattern of

\footnotetext{
* Corresponding author. Tel.: +1 970492 7340; fax: +1 9704927310.

E-mail address: Greg.McMaster(ars.usda.gov (G.S. McMaster).

1 Deceased.
}

development, and environmental conditions (e.g., temperature, photoperiod, nutrients, and water availability) can alter the developmental rates.

Several deficiencies remain in accurately predicting phenology in variable environments and management systems. One deficiency is that considerably less research has examined the impacts of water deficits (degree, timing, and history) on crop phenology (McMaster et al., 2009), despite the obvious influence of water deficits on some developmental phases (e.g., germination, emergence, grain filling). Further, phenological responses to water deficits vary among crops, cultivars, and developmental events. With few exceptions (e.g., SHOOTGRO, Zalud et al., 2003), crop phenology simulation models do not explicitly consider the influence of water deficits on phenology. Simulation models with more detailed energy balance submodels (e.g., ecosys, Grant et al., 1995; STICS, Brisson et al, 2003) can somewhat address phenological responses to water deficits by estimating and using plant temperature rather than air temperature, yet plant temperature alone will not necessarily predict phenological responses to water deficits correctly (McMaster et al., 2009). Without fundamental knowledge of development and quantification of phenological responses to water deficits for specific crops, a suitable foundation does not exist to 
predict crop development under variable environmental conditions to scientists, producers, and other practitioners. Such a foundation to transfer knowledge would also aid in developing decision support technologies and parameterization of crop models such as EPIC (Williams et al., 1989), ALMANAC (Kiniry et al., 1992), and GPFARM (McMaster et al., 2002a, 2003a; Ascough et al., 2007). In addition, mechanistic models for certain crops with detailed phenology submodels such as DSSAT (Jones et al., 2003), APSIM (McCown et al., 1996; Keating et al., 2003), and SHOOTGRO (McMaster et al., 1992b; Zalud et al., 2003) could improve their ability to simulate the effects of environmental factors such as limited soil water.

The objective of this paper is to provide an overview and basic statistical evaluation of the Phenology Modular Modeling System (PhenologyMMS) decision support technology software tool developed to simulate the phenology of various crops for different levels of soil water. In providing this overview, the PhenologyMMS Javabased interface and the general science behind the decision support software are briefly described.

\section{Materials and methods}

\subsection{Overview of PhenologyMMS decision support software}

The stand-alone PhenologyMMS V1.2 software tool consists of a Java interface integrated with FORTRAN modules to simulate phenological responses and has three primary goals: (1) to aid in adoption by a variety of users, the stand-alone program needs to be as simple as possible with minimal information or calibration required by the user; (2) to facilitate incorporation into other crop simulation models, standard programming practices and modularization approaches are incorporated into the design and programming of the process-based science modules; and (3) to serve as a learning tool, information is provided on crop phenology. The user interface has a series of screens to provide default inputs and parameters that can be modified by the user, runs the science modules to predict the occurrence of specific developmental stages, and allows users to view output results. Access to information such as the developmental sequence diagrams of crops, growth staging scales, and supporting documentation is accessed through the interface system and help buttons.

\subsection{Interface}

The user begins by selecting the crop (Choose Crop button) and weather file (Choose Location/Weather File button) for a site or loading a previously created scenario (Load Scenario button) as shown in the Begin Setup screen (Fig. 1). After selecting a crop, a "generic" cultivar is assumed as the default for each species. At this point, the user can then run the program by accepting all default inputs and parameters (although generally not recommended), or continue to modify other inputs. Crops currently simulated in PhenologyMMS V1.2 are winter and spring wheat, winter and spring barley, corn, sorghum, proso millet, hay/foxtail millet, and sunflower. Historical weather data for a variety of sites in the Great Plains, USA are provided (ASCII format), but users may create their own weather files if desired. When creating user weather files, the file structure of a provided weather file should be used, and daily maximum and minimum air temperature (in ${ }^{\circ} \mathrm{C}$ ) and precipitation (in $\mathrm{mm}$ ) need to be provided. Once the crop and site weather file have been chosen in the Begin Setup screen (Fig. 1), users may accept the defaults in the Set Inputs screen (Fig. 2) or change them if desired. The "Set Inputs" screen is accessed by the button in the Begin Setup screen. Initial inputs are set for each crop when the crop is selected, however, certain agronomic practices such as

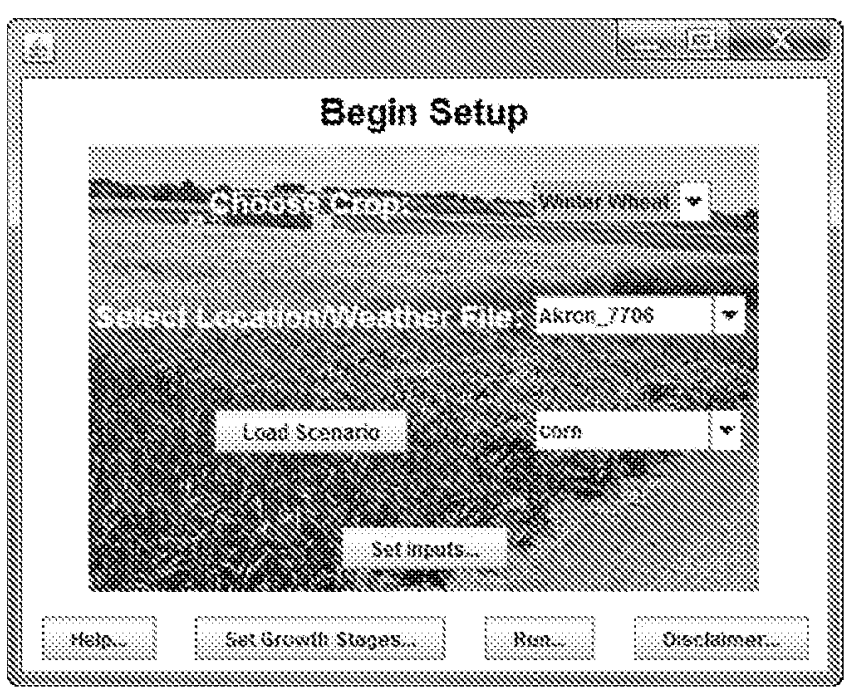

Fig. 1. Begin Setup screen. This screen is the first screen the user views when entering PhenologyMMS.

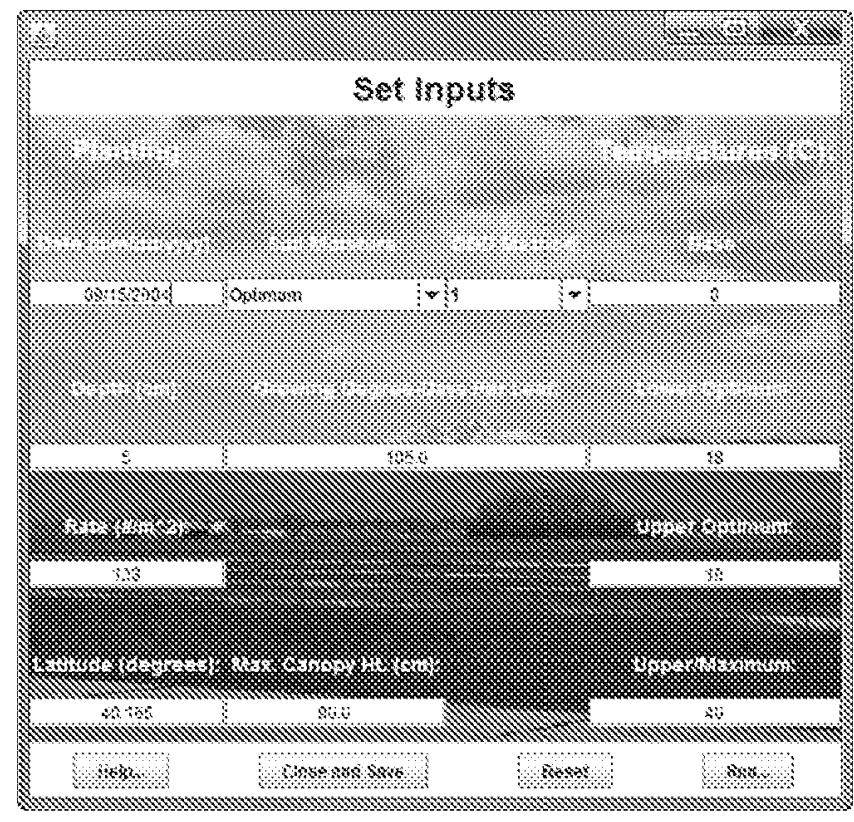

Fig. 2. Set Inputs screen. Example of initial inputs needed for the simulation model, with default values for winter wheat grown in northeastern Colorado, USA.

planting date vary by region and the defaults are set for northeastern Colorado, USA. Model inputs include latitude; planting practices; soil moisture condition; method for calculating thermal time as represented by growing degree-days ( ${ }^{\circ} \mathrm{C}$ day; GDD); base, optimal, and upper/maximum temperatures; and rate of leaf appearance.

Fig. 3 shows a key screen needed for the FORTRAN processbased modules that is accessed from the "Set Growth Stages" button of the Begin Setup screen. If the default generic cultivar is not desired, limited varietal information is available and may be selected with the "Variety" button at the bottom of the screen. The general layout of the "Set Growth Stages" screen is similar for all crops. A series of rows represent different developmental phases specifically identified for each crop, with default values that can be changed by the user for each of four options (i.e., columns) to be used to simulate the growth phases: 


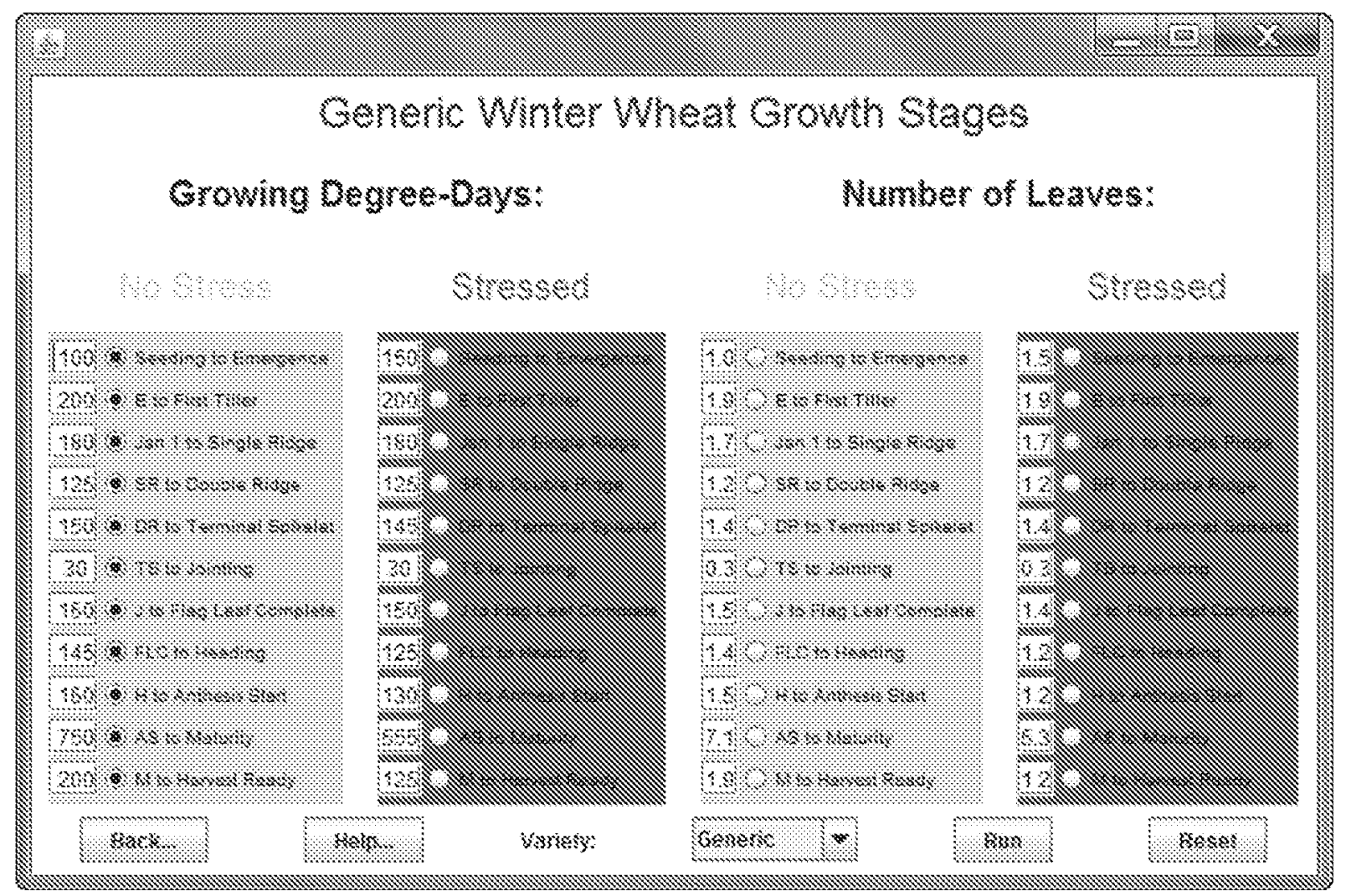

Fig. 3. Set Growth Stages screen. The default parameters for developmental stages for a generic winter wheat plant are shown.

- No stress refers to non-limiting conditions of an environmental factor, and we usually consider the environmental factor to be soil water availability. This option should be selected for irrigated or high rainfall conditions.

- Stress refers to the most limiting value of the environmental factor not leading to terminal stress (i.e., death of the plant). This option should be selected for most rainfed situations where soil water is often severely limiting, but not lethal. Because conditions are often between the No stress and Stress options, either the user can estimate which option is closest to the conditions to be simulated and select that option, or change the default values of one of the options to be intermediate between the two extremes.

- Within both the No stress and Stress options, two related estimates of thermal time (i.e., growing degree-days, GDD, or number of leaves produced between developmental events, NL) can be selected. Number of leaves for an interval is multiplied by the phyllochron (the thermal time between appearance of successive leaves, ${ }^{\circ} \mathrm{C}$ days) to convert to thermal time. This approach is based on predicting plant development by integrating it with the main stem leaf number (Rickman and Klepper, 1995: McMaster, 2005).

The default selection for the screen is to use the No stress option and GDD method. Any combination of the four options within a row may be selected regardless of selections in the other rows. As with the other screens, the user may run the model after accepting or modifying the parameters in the Set Growth Stages screen. When the Run button in any screen is selected, the Output screen (Fig. 4) is automatically generated, usually within a second or so. Fig. 4 shows the end of the Output file that can be saved by the user with all of the developmental events (= number of rows) shown in Fig. 3 for the crop. At the top of the Output file, all information on the initial inputs and parameter values selected in the Begin Setup (Fig. 1), Set Inputs (Fig. 2), and Set Growth Stages (Fig. 3) screens is echoed back into the Output screen. The user can save the Output screen, and also save the simulation scenario (i.e., values selected in Figs. 1-3) if desired, and then retrieve this scenario for simulation at a later time.

\subsection{PhenologyMMS FORTRAN process-based science modules}

The Java interface described above is used to input the parameters and drivers (e.g., weather) used by the separate processbased science modules coded in FORTRAN. A detailed description of the process-based science modules is provided in McMaster et al. (Submitted for publication), and only a brief description is provided here. The modules are primarily based on:

1. Simplifying an earlier and more detailed phenology model for wheat and barley (SHOOTGRO, McMaster et al., 1992b; Zalud et al., 2003), and

2. Summarizing and quantifying the entire developmental sequence of the shoot apex of other crops (e.g., corn, proso millet, hay millet, sorghum, and sunflower) and correlating the sequences with commonly used growth stage scales. Particular emphasis was focused on how water deficits impact the phenology of the crop. The template for this synthesis was based on that developed by McMaster et al. (1992a), and expanded by McMaster et al. (2005).

A series of steps were used to create the Set Growth Stages screen (Fig. 3) for each crop, which is important for simulating phenology. An overview describing the steps is provided here. The first step was to use the literature to summarize and quantify, to the extent possible, the entire developmental sequence 


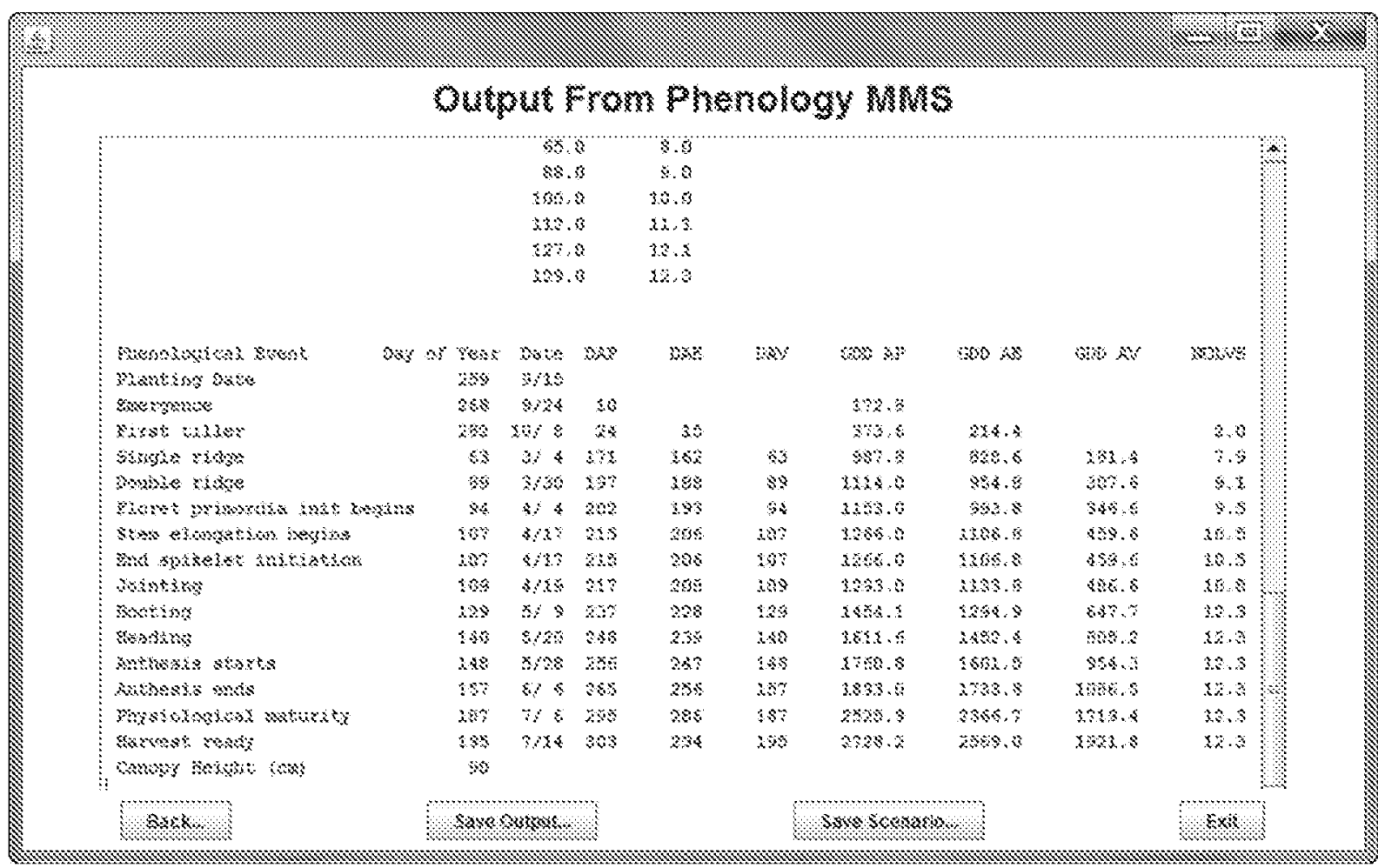

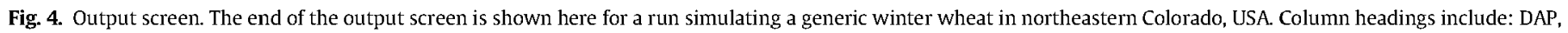

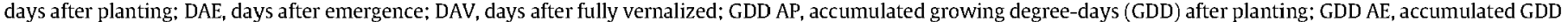
after emergence; GDD AV, accumulated GDD after fully vernalized; and NOLVS, which is the Haun stage (Haun, 1973) and is the number of leaves produced on the main stem.

of the shoot apex and correlate the sequences with commonly used growth stage scales. Once the developmental sequence diagrams under optimal conditions were created for a generic crop, diagrams for the sequential phenological responses to water deficits needed to be determined (McMaster et al. 2005). The phenological responses to water deficits diagrams were used to produce the Set Growth Stages screen (Fig. 3) in the PhenologyMMS program, and new crops can be readily added once these diagrams are created. Two other science modules are included in PhenologyMMS: seedling emergence and canopy height. The seedling emergence model is a simplified version of that incorporated into the SHOOTGRO model (Wilhelm et al., 1993). Three factors control the rate of seedling emergence: planting depth, soil moisture near the seed, and temperature. Soil moisture primarily controls the beginning of imbibition and germination and temperature then drives the rate of emergence. Planting depth influences the time of emergence mainly by the time for seedlings to emerge.

The stand-alone version of PhenologyMMS does not have a soil water balance module, so a surrogate approach to vary soil moisture conditions while simulating seedling emergence is to use precipitation during this time period. Daily rainfall amounts from 5 to $7 \mathrm{~mm}$ increments the soil moisture category to the next higher level of soil moisture. If rainfall events are from 7 to $12 \mathrm{~mm}$, the soil moisture category is incremented two levels. If the starting level of soil moisture is planted in dust, then accumulation of thermal time does not begin until the soil moisture category is at least dry. Crop-specific parameters (Table 1 for winter and spring wheat) for thermal time accumulation (using air temperature) from planting to start of germination are based on four general categories of soil moisture in the seedbed layer: optimum ( $>45 \%$ water-filled pore space), medium (35-45\%), dry $(25-35 \%)$, and planted in dust $(<25 \%)$. The user does not need to precisely estimate these values, rather the category may be
Table 1

Germination and seecling elongation rate parameters for wheat under specific seedbed conditions.

\begin{tabular}{lc}
\hline Soil moisture & Wheat \\
\hline${\text { Germination }\left(\sum G D D^{c}\right)}_{\text {Optimum }^{\mathrm{a}}}$ & \\
Medium & 80.0 \\
Dry & 90.0 \\
Dust $^{\mathrm{b}}$ & 110.0 \\
Elongation rate $(\mathrm{mm} / \mathrm{GDD})^{\text {Optimum }}$ & 700.0 \\
Medium & \\
Dry & 0.50 \\
Dust & 0.40 \\
Planting depth $(\mathrm{cm})$ & 0.33 \\
\end{tabular}

${ }^{a}$ Seedbed conditions are based on \% water-filled pore space: optimum ( $>45 \%)$, medium (35-45\%), dry (25-35\%), and dust $(<25 \%)$.

b Soil moisture in this category is below the minimum threshold to initiate imbibition processes.

${ }^{c}$ Accumulated growing degree-days (GDD) required to initiate germination.

selected based on general conditions. Following germination, thermal time drives the elongation rate from a planted depth until emergence at the soil surface. Elongation rates are reduced as soil moisture availability decreases.

PhenologyMMS contains a canopy height module that allows for two linear phases of crop canopy growth: from planting to beginning of internode elongation, and from internode elongation to final plant height. Currently the growth rate is not reduced by water deficits, so the maximum potential canopy height is simulated. This module only uses the phenology component to determine when the development phases occur and final canopy height is part of the output. 


\subsection{Data sets and model evaluation methods}

Creating PhenologyMMS required collecting data sets for both model development and validation for each crop, yet comprehensive phenological data sets examining responses to variable water deficits are rare in general for major agronomic crops, and sometimes non-existent for many agronomic crops (McMaster et al., 2009). Detailed evaluation of PhenologyMMS for all crops is presented in McMaster et al. (Submitted for pubication), and in this paper results are presented only for winter and spring wheat. These crops were chosen as the experimental data sets are representative of those commonly available to many users in that soil water deficit levels were not rigorously measured, a variety of cultivars were grown in a diversity of environments, and planting dates and management practices varied considerably. Because the data sets contained diverse cultivars and conditions, the default parameters for a generic winter or spring wheat cultivar were used in all simulations, with the exception that planting date was changed to the actual planting date. This evaluation would be typical for users that have little information or do not wish to get into a greater level of detail in running the program.

The following data sets were used for evaluating winter and spring wheat phenology: (1) a 2-year irrigation study for 12 cultivars at Fort Collins, CO and Akron, CO (McMaster et al., 2003a,b); (2) a 6-year tillage by residue cover study at Fort Collins, CO (McMaster et al., 2002b); (3) a 2-year planting date by heated soil study at Fort Collins, CO (McMaster et al, 2003b); (4) a 21 site-year study across the Great Plains, USA for a variety of cultivars, environments, and management (McMaster and Smika, 1988); and (5) a 6-year study examining spatial variation in phenology across a landscape about 15 miles east of Fort Collins, CO (unpublished data). Combining all experiments, over 25 cultivars were measured at regular intervals (often three days per week) for when the developmental stages of seedling emergence, jointing, flag leaf blade growth complete, heading, anthesis, and physiological maturity occurred in each experiment.

Relative error (RE) and root mean square error (RMSE) model evaluation statistics were calculated to compare modeled results to measured data. Relative error was expressed in percent as:

$\mathrm{RE}=\frac{(\bar{P}-\bar{O})}{\overline{0}} 100$

where $\bar{P}$ is the predicted mean and $\bar{O}$ is the observed mean. The RMSE was calculated by:

RMSE $=\sqrt{\frac{\sum_{i=1}^{n}\left(P_{i}-O_{i}\right)^{2}}{n}}$

where $P_{i}$ is the $i$ th predicted value, $O_{i}$ is the $i$ th observed value, and $n$ is the number of data pairs. In some experiments, such as those that evaluated tillage and residue cover practices, treatment effects resulted in different observed dates for some developmental events (although the mechanisms explaining the differences were not clear). PhenologyMMS simulated the same day for the developmental stage regardless of treatment.

\section{Results and discussion}

An illustration of PhenologyMMS simulation model performance is presented for seedling emergence, floral initiation, flowering, and physiological maturity developmental events for winter and spring wheat. The RMSE for different developmental events ranged from 7.2 to 12.4 and 2.6 to 6.9 days for winter and spring wheat, respectively (Fig. 5). Model bias, or relative error (RE), for all developmental stages was slightly negative for winter wheat, indicating a bias towards simulating a developmental event earlier than observed; the slightly positive RE for spring wheat indicated a tendency to simulate later dates than observed.

Cultivar variation in the phase from seedling emergence to floral initiation can be considerable for winter wheat and has been noted in the literature (e.g., Jamieson et al., 2007; McMaster and Wilhelm, 1998). Our results showed the highest RMSE for this phase (as indicated by the developmental phase of jointing) of any developmental phase (12.4 days), and using default generic parameters as done in this evaluation cannot capture this variation. Furthermore, winter wheat genotypes have vernalization and often photoperiod, requirements that must be satisfied before floral initiation can occur. The PhenologyMMS model currently does not incorporate a photoperiod factor and assumes that vernalization has been satisfied by 1st January. This assumption is normally met in the environments and planting dates used in our evaluation data sets (based on running vernalization models and unpublished data from bringing in plants from the field to the greenhouse which subsequently flowered). The large variability noted in Fig. 5 for winter wheat reflects the likely need to include vernalization and photoperiod factors into the model to further improve the model. The duration of grain filling is significantly influenced by the interaction of temperature and water deficits, and genotypes can vary considerably in their response to these two environmental factors (McMaster and Wilhelm, 2003; McMaster et al., 2009). RMSE increased for winter and spring wheat for simulating physiological maturity when compared to flowering (Fig. 5).

A further illustration of PhenologyMMS simulation performance is provided by showing an application for assessing expected developmental timing across the Great Plains for a Regional Wheat Production Guide (MCMaster and Wilhelm, 2010). In this application, all default values were used to simulate winter wheat jointing, anthesis, and maturity dates across locations throughout the Great Plains using historical weather data. Two scenarios were run representing the extremes of high (GN, irrigated/high precipitation) and low (GS, dryland, low precipitation) soil water levels. The general expected patterns of earlier anthesis and maturity under high water deficits and lower latitudes were observed, and mean simulated dates fit within the expected dates normally observed for the locations (Table 2).

One advantage of PhenologyMMS is that rather than using one set of parameters (as done in most model evaluation) to calculate phenology across a range of conditions at a location, the parameter set is adjusted to reflect the level of water deficits. Therefore, applications such as that shown in Table 2 are able to provide more realistic estimates of developmental stages across environments varying in water deficits than would a model using a single parameter set.

The evaluation and application results are encouraging and show that PhenologyMMS can adequately simulate wheat phenology. While not shown here, evaluation results for the other crops usually had lower RMSEs than for wheat (McMaster et al., Submitted for publication). This suggests that PhenologyMMS can be used as a decision tool for certain management decisions requiring knowledge of crop developmental stages. Certainly the accuracy of inputs and initial conditions are critical in quantifying model predictive ability, and decision makers will need to consider the degree of error (e.g., RMSE magnitude) acceptable in accepting or modifying default values.

\section{Summary and future work}

PhenologyMMS is intended to provide a simple and easy to use program to predict and understand crop phenology and how phenology responds to varying water deficits. The evaluation 

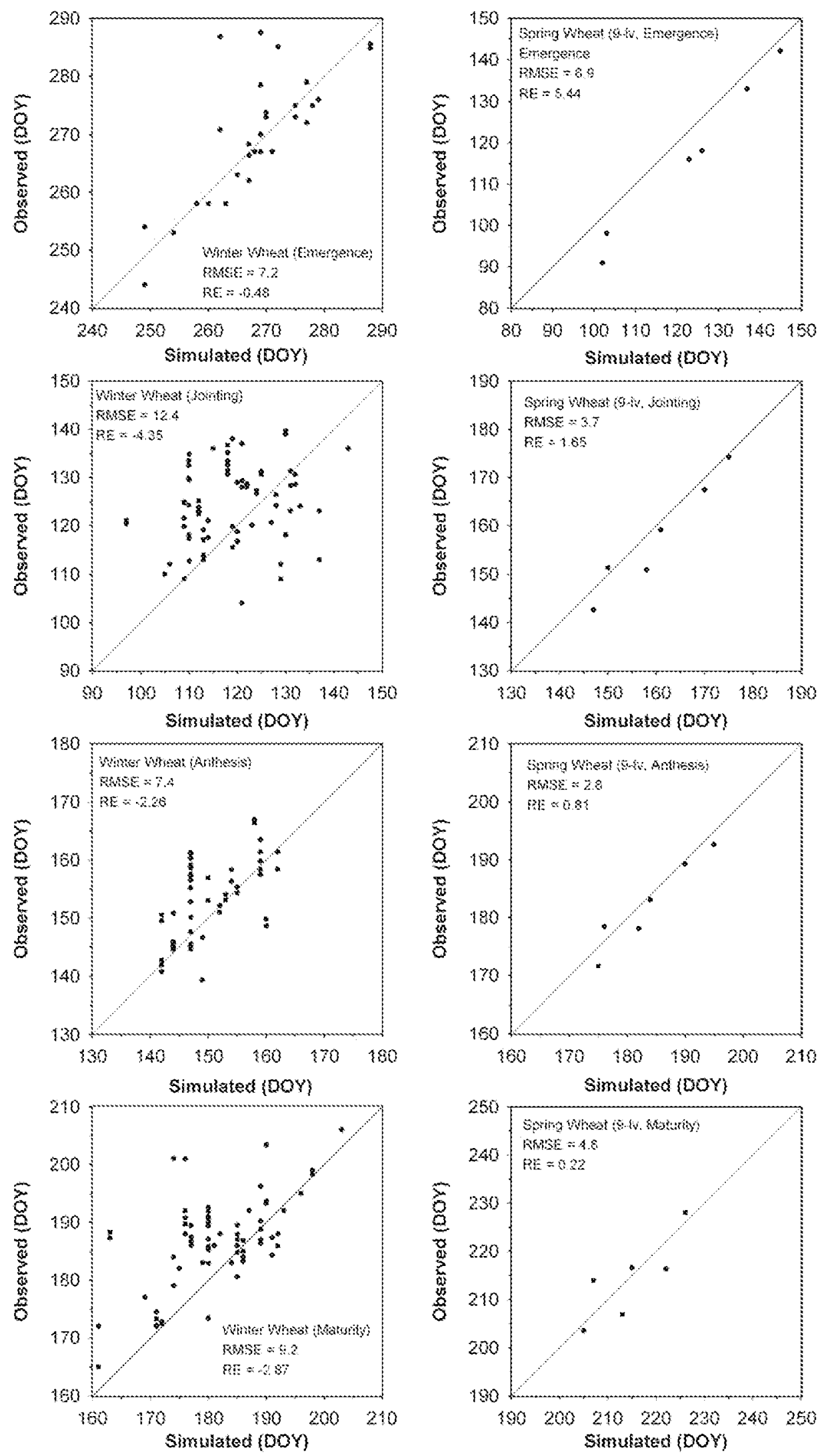

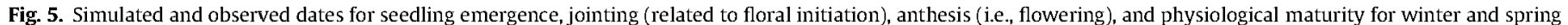
wheat.

presented here, even when genotype, environmental, and management information was limited, resulted in RMSE's ranging from 2.6 to 6.9 days for generic spring wheat and 7.2 to 12.4 days for generic winter wheat, depending on the developmental event. This indicates that PhenologyMMS 1.2 can reasonably predict crop development to aid in crop management decision support over a 
Table 2

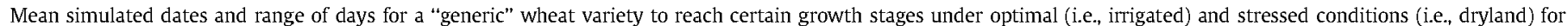

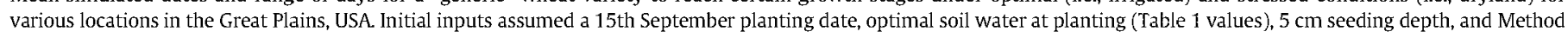

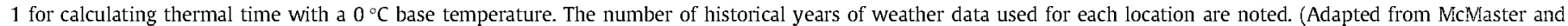
Wilhelm (2010)).

\begin{tabular}{|c|c|c|c|c|c|c|c|c|}
\hline \multirow[t]{3}{*}{ Location } & \multirow[t]{3}{*}{ \# Years } & \multicolumn{7}{|c|}{ Mean date/range (\# days) } \\
\hline & & \multirow{2}{*}{$\begin{array}{l}2 \text { Leaves } \\
\text { Optimal }\end{array}$} & \multicolumn{2}{|l|}{ Jointing } & \multicolumn{2}{|l|}{ Anthesis } & \multicolumn{2}{|l|}{ Maturity } \\
\hline & & & Optimal & Stress & Optimal & Stress & Optimal & Stress \\
\hline Akron, CO & 29 & Oct. 10 & Apr. 28 & Apr. 27 & Jun. 2 & May 29 & Jul. 9 & Jun. 28 \\
\hline Range & & -6 to 11 & -19 to 21 & -19 to 22 & -13 to 14 & -15 to 15 & -9 to 12 & -10 to 12 \\
\hline Colby, KS & 21 & Oct. 8 & Apr. 18 & Apr 17 & May 22 & May 18 & Jun. 27 & Jun. 16 \\
\hline Range & & -5 to 9 & -17 to 19 & -16 to 19 & -14 to 14 & -13 to 14 & -8 to 12 & -9 to 13 \\
\hline Durant, OK & 74 & Sep. 30 & Mar. 9 & $\operatorname{Mar} 9$ & Apr. 12 & Apr. 8 & May 21 & May 9 \\
\hline Range & & -3 to 4 & -24 to 30 & -24 to 30 & -22 to 24 & -21 to 24 & -16 to 22 & -18 to 20 \\
\hline Fort Collins, $\mathrm{CO}$ & 30 & Oct. 14 & May 1 & May 1 & Jun. 5 & Jun. 1 & Jul. 13 & Jul. 1 \\
\hline Range & & -10 to 10 & -24 to 12 & -24 to 12 & -25 to 8 & -25 to 8 & -18 to 9 & -19 to 9 \\
\hline Rocky Ford, co & 28 & Oct. 8 & Apr. 14 & Apr. 14 & May 18 & May 14 & Jun. 25 & Jun. 13 \\
\hline Range & & -5 to 23 & -20 to 14 & -21 to 13 & -20 to 17 & -20 to 13 & -15 to 16 & -17 to 14 \\
\hline Shelton, NE & 14 & Oct. 9 & Apr. 27 & Apr. 26 & May 29 & May 25 & Jul. 3 & Jun. 22 \\
\hline Range & & -4 to 4 & -12 to 14 & -12 to 15 & -11 to 11 & -11 to 11 & -4 to 10 & -7 to 10 \\
\hline Sidney, NE & 23 & Oct. 14 & May 3 & May 3 & Jun. 6 & Jun. 2 & Jul. 13 & Jul. 2 \\
\hline Range & & -7 to 9 & -13 to 17 & -14 to 16 & -14 to 12 & -14 to 13 & -7 to 9 & -8 to 9 \\
\hline Sterling, CO & 13 & Oct. 10 & Apr. 27 & Apr. 26 & May 31 & May 27 & Jul. 7 & Jun. 26 \\
\hline Range & & -5 to 3 & -11 to 9 & -10 to 10 & -11 to 7 & -11 to 7 & -8 to 7 & -9 to 8 \\
\hline Stratton, CO & 19 & Oct. 8 & Apr. 21 & Apr. 21 & May 27 & May 23 & Jul. 3 & Jun. 22 \\
\hline Range & & -3 to 4 & -10 to 16 & -11 to 16 & -10 to 11 & -10 to 11 & -7 to 10 & -7 to 10 \\
\hline Walsh, CO & 12 & Oct. 6 & Apr. 7 & Apr. 7 & May 14 & May 10 & Jun. 21 & Jun. 9 \\
\hline Range & & -5 to 4 & -8 to 15 & -8 to 14 & -11 to 10 & -11 to 10 & -7 to 8 & -9 to 9 \\
\hline
\end{tabular}

region. Planned PhenologyMMS enhancements based on feedback from users and evaluation results include: (1) adding and validating more crops, (2) including more approaches for estimating thermal time (i.e., more temperature response functions), (3) adding vernalization and photoperiod factor submodels, (4) providing more variety choices, (5) enhancing the information system, and (6) having more historical weather data included with the software and provide options to change weather data for different possible environmental scenarios (e.g., hot and dry, cool and wet, etc.). To better quantify phenological responses to varying water deficits, PhenologyMMS is also being integrated into an existing crop growth model that has a mechanistic water balance submodel. The ultimate goal is to incorporate a simple water balance submodel into PhenologyMMS so that the default parameters are adjusted for water deficits between the two extremes.

\section{Acknowledgments}

Mr. B. Riebau wrote much of the original code for the Java interface, and Drs. G. Varvel and D. Francis, Mr. M. Schlemmer, Ms. K. Ruwe, and Mr. P. Koerner were instrumental in obtaining and providing the MSEA corn phenology data sets used in developing the parameters for corn. Dr. R.L. Vanderlip provided invaluable insights into sorghum development, and Drs. J.W. White, D.M. Blumenthal, and S. Adiku provided valuable reviews of the work. The PhenologyMMS software may be downloaded from http://arsagsoftware.ars.usda.gov.

\section{References}

Ascough II, J.C., McMaster, G.S., Andales, A.A., Hansen, N.C., Sherrod, L.A., 2007. Evaluating GPFARM crop growth, soil water, and soil nitrogen components for Colorado dryland locations. Transactions of the ASABE 50, 1565-1578.

Brisson, N., Gary, C., Justes, E., Roche, R., Mary, B., Ripoche, D., Zimmer, D., Sierra, J. Bertuzzi, P., Burger, P., Bussiere, F., Cabidoche, Y.M., Cellier, P., Debaeke, P., Gaudillere, J.P., Henault, C., Maraux, F., Seguin, B., Sinoquet, H., 2003. An overview of the crop model STICS. European Journal of Agronomy 18, 309-332.

Grant, R.F., Kimball, B.A., Pinter Jr., P.J., Wall, G.W., Garcia, R.L., LaMorte, R.L., Hunsaker, D.J., 1995. Energy exchange between the wheat ecosystem and the atmosphere under ambient vs. elevated atmospheric $\mathrm{CO}_{2}$ concentrations: testing of the model ECOSYS with data from the free air $\mathrm{CO}_{2}$ enrichment (FACE) experiment. Agronomy Journal 87, 446-457.
Haun, J.R., 1973. Visual quantification of wheat development. Agronomy Journal 65 $116-119$.

Jamieson, P.D., Brooking, I.R., Semenov, M.A., McMaster, G.S., White, J.W., Porter, J.R., 2007. Reconciling alternative models of phenological development in winter wheat. Field Crops Research 103, 36-41.

Jones, J.W., Hoogenboom, G., Porter, C.H., Boote, K.J., Batchelor, W.D., Hunt, L.A., Wilkens, P.W., Singh, U., Gijsman, A.J., Ritchie, J.T., 2003. The DSSAT cropping system model. European Journal of Agronomy 18, 235-265.

Keating, B.A., Carberry, P.S., Hammer, G.L., Probert, M.E., Robertson, M.J., Holzworth, D., Huth, N.I., Hargreaves, J.N.G., Meinke, H., Hochman, Z., McLean, G., Verburg, K., Snow, V., Dimes, J.P., Silburn, M., Wang, E., Brown, S., Bristow, K.L., Asseng, S., Chapman, S., McCown, R.L., Freebairn, D.M., Smith, C.J., 2003. An overview of APSIM, a model designed for farming systems simulation. European Journal of Agronomy 18, 267-288.

Kiniry, J.R., Williams, J.R., Gassman, P.W., Debaeke, P., 1992. A general processoriented model for two competing plant species. Transactions of the ASAE 35, 801-810.

McCown, R.L., Hammer, G.L., Hargreaves, J.N.G., Holzworth, D.P., Freebairn, D.M., 1996. APSIM: a novel software system for model development, model testing and simulation in agricultural systems research. Agricultural systems 50, 255271.

McMaster, G.S., 2005. Phytomers, phyllochrons, phenology and temperate cereal development. Journal of Agricultural Science (Cambridge) 143, 137150.

McMaster, G.S., Smika, D.E., 1988. Estimation and evaluation of winter wheat phenology in the central Great Plains. Agricultural and Forest Meteorology 43, 1-18.

McMaster, G.S., Wilhelm, W.W., 1998. Is soil temperature better than air temperature for predicting winter wheat phenology? Agronomy Journal 90 602-607.

McMaster, G.S., Wilhelm, W.W., 2003. Phenological responses of wheat and barley to water and temperature: improving simulation models. Journal of Agricultural Science (Cambridge) 141, 129-147.

McMaster, G.S., Wilhelm, W.W., 2010. The wheat plant. Development, growth, and yield. In: Peairs, F.B. (Ed.), Wheat Production and Pest Management for the Great Plains Region. Colorado State University Extension XCM235, Fort Collins, CO, pp. 7-16.

McMaster, G.S., Morgan, J.A., Wilhelm, W.W., 1992a. Simulating winter wheat spike development and growth. Agricultural and Forest Meteorology 60, 193-220.

McMaster, G.S., Wilhelm, W.W., Morgan, J.A., 1992b. Simulating winter wheat shoot apex phenology. Journal of Agricultural Science (Cambridge) 119, 1-12.

McMaster, G.S., Ascough II, J.C., Dunn, G.A., Weltz, M.A., Shaffer, M., Palic, D., Vandenberg, B., Bartling, P., Edmunds, D., Hoag, D., Ahuja, L.R., 2002a. Application and testing of GPFARM: a farm and ranch decision support system for evaluating economic and environmental sustainability of agricultural enterprises. Acta Horticulturea 593, 171-177.

McMaster, G.S., Palic, D.B., Dunn, G.H., 2002b. Soil management alters seedling emergence and subsequent autumn growth and yield in dryland winter wheatfallow systems in the Central Great Plains on a clay loam soil. Soil \& Tillage Research 65, 193-206. 
McMaster, G.S., Ascough II, J.C., Nielsen, D.C., Byrne, P.F., Haley, S.D., Shaffer, M.J. Andales, A.A., Dunn, G.A., 2003a. GPFARM plant model parameters: Complications of varieties and the genotype $\times$ environment interaction in wheat. Transactions of the ASAE 46, 1337-1346.

McMaster, G.S., Wilhelm, W.W., Palic, D.B., Porter, J.R., Jamieson, P.D., 2003b. Spring wheat leaf appearance and temperature: extending the paradigm? Annals of Botany 91, 697-705.

McMaster, G.S., Wilhelm, W.W., Frank, A.B., 2005. Developmental sequences for simulating crop phenology for water-limiting conditions. Australian Journal of Agricultural Research 56, 1277-1288.

McMaster, G.S., White, J.W., Wilhelm, W.W., Jamieson, P.D., Baenziger, P.S., Weiss A., Porter, J.R., 2009. Simulating crop developmental responses to limited soil water. In: Ahuja, L.R., Reddy, V.R., Anapalli, S.A., Yu, Q. (Eds.), Modeling the Response of Crops to Limited Water: Recent Advances in Understanding and Modeling Water Stress Effects on Plant Growth Processes. Advances in Agricultural Systems Modeling. Trans-disciplinary Research, Synthesis, and Applications, vol. 1. ASA-SSSA-CSSA publication.
McMaster, G.S., Ascough II, J.C., Edmunds, D.A., Nielsen, D.C., Prasad, P.V.V. Wilhelm, W.W., Submitted for publication. Simulating crop phenological responses to water stress using the PhenologyMMS software component Applied Engineering in Agriculture.

Rickman, R.W., Klepper, B., 1995. The phyllochron: where do we go in the future? Crop Science 35, 44-49.

Wilhelm, W.W., McMaster, G.S., Rickman, R.W., Klepper, B., 1993. Above-ground vegetative development and growth of winter wheat as influenced by nitrogen and water availability. Ecological Modelling 68, 183-203.

Williams, J.R., Jones, C.A., Kiniry, J.R., Spanel, D.A., 1989. The EPIC crop growth model. Transactions of the ASAE 32, 497-511.

Zalud, Z., McMaster, G.S., Wilhelm, W.W., 2003. Evaluating SHOOTGRO 4.0 as a potential winter wheat management tool in the Czech Republic. European Journal of Agronomy 19, 495-507. 